\title{
Owls in Harry Potter: a Functional Stylistic Study in Children's Literature
}

\author{
Wenxiao Zhao \\ School of Foreign Languages \\ University of Jinan \\ Jinan, China
}

\author{
Yong Wang \\ School of Foreign Languages \\ University of Jinan \\ Jinan, China
}

\begin{abstract}
Harry Potter was supposed to be a series of children's literature whose author J.K. Rowling narrated a year's experience and personalities of the characters in everchanging circumstances. As an encyclopedia consisting of world experience, the novel included a wide range of human activities of most transitivity types. This paper was trying to carry out a functional stylistic study on the Owls in Harry Potter with the aim of discovering their characteristics based on Halliday's systemic functional linguistics.
\end{abstract}

Keywords-functional stylistics; Harry Potter; transitivity processes; children's literature; image of owls

\section{INTRODUCTION}

Harry Potter is a set of seven fantasy novels written by British author J.K. Rowling. It tells stories about a wizard boy, Harry Potter, whose parents were murdered by an evil wizard named Lord Voldemort when he was too little to remember. Having lived in the Muggles' (who don't know the magic) world for several years, he went to the Hogwarts school to learn to be a wizard where he made friends with Ron Weasley and Hermione Granger. As a children literature, the Harry Potter is popular all over the world, and researchers have studied it from different perspectives. However, most studies in about Harry Potter have only been carried out in a small number of areas such as literature criticism and translations (Liu \& Zhao, 2015: 152). Few studies have focused on the characters in the novel based on linguistic approaches. In the present study, we are concentrated in the stylistic analysis of the character of the owls by means of the transitivity system in the area of systemic functional linguistics.

Stylistics is a discipline adopting modern linguistic theories and methods to study style (Wright \& Hope, 2002) of literary works. It is devoted to 'style'. Leech and Short (2007: 11) believe that 'style' is the selection from a total linguistic repertoire. The 'style of $\mathrm{X}$ ' refers through 'style' to characteristics of language use, and correlates these with some extralinguistic X. They name it as stylistic domain, which is complicated and difficult to study. It is on the safest ground to think of style as the 'linguistic characteristics of a particular text'. (2007: 11-13) Therefore, to study style is tantamount to explain something in a certain text.
Literary Stylistics includes all kinds of stylistic practices that study literary texts (Li \& Wang, 2015). It holds the goal of explaining the relation between language and artistic function (Leech \& Short, 2007: 13). The modern term denominated 'Systemic Functional Stylistics' (SFS hereafter) is introduced when we refer to the stylistic group on the basis of Halliday's systemic functional linguistic theory using literary texts as objects and thus belongs to Literary Stylistics. Historically, SFS started around the year 1971 when Halliday published his thesis "Linguistic Function and Literary Style: An Inquiry into the Language of William Golding's The Inheritor" (1971: 330-368). Therefore SFS studies a text's thematic and aesthetic effects by exploring language structures. It is via the analysis of the literary texts that we are able to increase our understanding of the linguistic systems and of how it enables speakers and writers to produce and process a coherent meaning. It makes literary works better comprehended and appreciated (Shen, 2006: 23).

In the present paper, we try to adopt the theories of SFS to explore the linguistic patterns which have close relations with the Owls in Harry Potter. It makes us a better understanding of how the writer conveys the information of this magic creature via different transitivity processes.

\section{Methodology}

\section{A. Subjets}

In general, this paper is a corpus-based study. We employed the first volume of Harry Potter, that is, Harry Potter and the Philosopher's Stone (Rowling, 1998). Totally it contains more than 78,000 words. It is accepted by the public that Harry Potter and the Philosopher's Stone has had enormous influence as a book and then as a film, and is therefore very important in constructing and reinforcing ideologies of education, gender, and nature. That is to say, it could be treated as an encyclopedia to a certain extent in representing the world experience in different perspectives.

Originally the novel Harry Potter was supposed to be a series of children's books full of imagination, humor and suspense. Like a children psychological analyst, Rowling narrates a year's experience of the characters in each book and explores the development of characters' personalities in ever-changing circumstances. Based on these two factors, we 
choose the original volume as the corpus in our study of the characters of the owls.

\section{B. Instruments and Procedures}

In order to retrieve all instances of in this corpus, the present study employs WordSmith 3.0 as the retrieval program, which was developed by Mike Scott. It is a set of lexical analysis tools operating under windows on text files stored on any drive. It can retrieve search items specified by users from large amount of data, show the total number of its occurrence, and display all the occurrences of the search items in concordance lines of context, with the search items being highlighted on the screen. Three tools involved are WordList, Concordance and KeywordList.

We use the WordList function to generate a list of ordered words that appear in the target files. These can be utilized to compare the frequency of a word in the text; within this tool, we can understand the token of the item 'owl'. Compared with the other creatures in this novel, owls appear more frequently. They have drawn us more attention than other animals for their highlighted representivity in the magical school. WordSmith can compare the clusters that appear in the target files with that appear in a reference corpus to generate a list of KeyWords. Thanks to this function, we can build our prepared keywords for our study of transitivity processes of the owls. Finally, by using the Concordance tool, we can obtain lots of examples of a word or phrase, in their contexts. The Concordance tool generates Concordance lines from one or more target text chosen by the user. In our study, we use mainly the Concordance function to get samples in lines for our analysis by searching prepared keywords, as fly, send, message, etc.

\section{THEORETICAL BACKGROUNDS}

\section{A. Transitivity System}

The theoretical basis of SFS is Systemic Functional Grammar (SFG hereafter) created by Halliday. SFG is a study of how meanings are built up through the use of words and other linguistic forms such as tone and emphasis. Halliday thinks language is 'a system of meanings', each of which offers the speaker (or writer) a choice of ways of expressing of meanings. People use language to express meanings in specific situations, and the form of the language that they used is influenced by those situations. All languages are organized around two principal kinds meaning, the 'ideational', and the 'interpersonal'. On the basis of the two components, the 'textual' is formed. The three are called Metafunctions (Halliday, 2000).

In this paper, we mainly talk about the transitivity system which belongs to the ideational function. According to Bloor\& Bloor (1995: 9), language is used to organize, understand and express our perceptions of the world and of our own consciousness. This is recognized as the Ideational Function. It is comprised of the Experiential and the Logical. The Experiential Function is largely concerned with content or ideas. The Logical Function is devoted with the logical relationship between ideas. The world of human beings is full of experience. Transitivity System construes the world of experience into a manageable set of process types. In the English Transitivity System, generally there are six processes: the Material Processes, the Mental Process, the Relational Process, the Behavioral Process, the Verbal Process and the Existential Process. Among them, Material, Mental and Relational are the three main types.

\section{B. Processes in Cardiff Grammar}

In Cardiff Grammar (Fawcett, 2002), there occurs a more detailed categorization. According to Cardiff Grammar, the author categorized the material processes into three branches in "Fig. 1": one participant (or role) process, illustrated by the first group of examples, two participants process, illustrated by the second group as well as three participants process, illustrated by the third group.

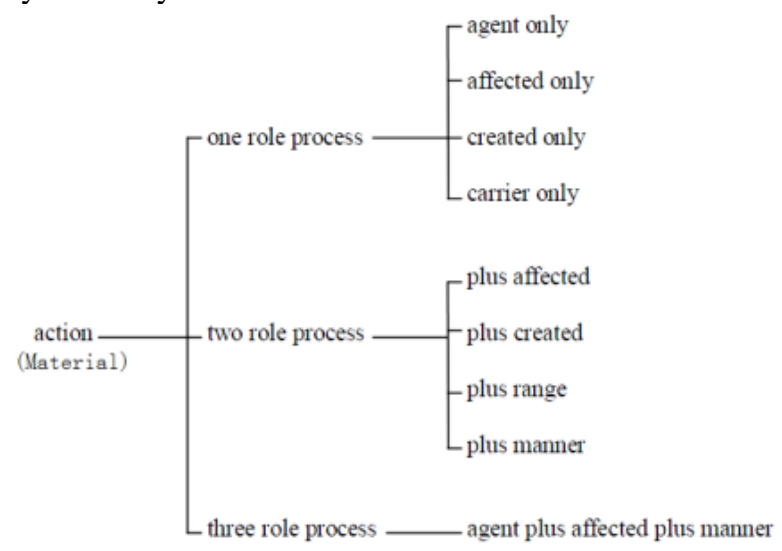

Fig. 1. The current System Network for Action Processes in the Cardiff Grammar adopted from Fawcett (2002).

Group 1:

$\mathrm{Ag}+$ Pro: She runs.

Af + Pro: Her cat has died.
$\mathrm{Ca}+$ Pro: My leg hurt.

Cre + Pro: He was born in 1990 . 
Group 2:

$\mathrm{Ag}+$ Pro + Af: He cuts himself.

$\mathrm{Ag}+$ Pro + Cre: He baked a cake.

$\mathrm{Ag}+$ Pro + Ra: He climbed Mountain.

Ag + Pro + Ma: He behaved well.

\section{Group 3:}

$\mathrm{Ag}+$ Pro + Af + Ma: My aunt treats me well.

The mental processes, demonstrated in "Fig. 2" show a tied relationship with the verb that we employ in the clause. For example, the desiderative process can be realized by 'want' while 'study' represents an agent-cognizant process subtype.

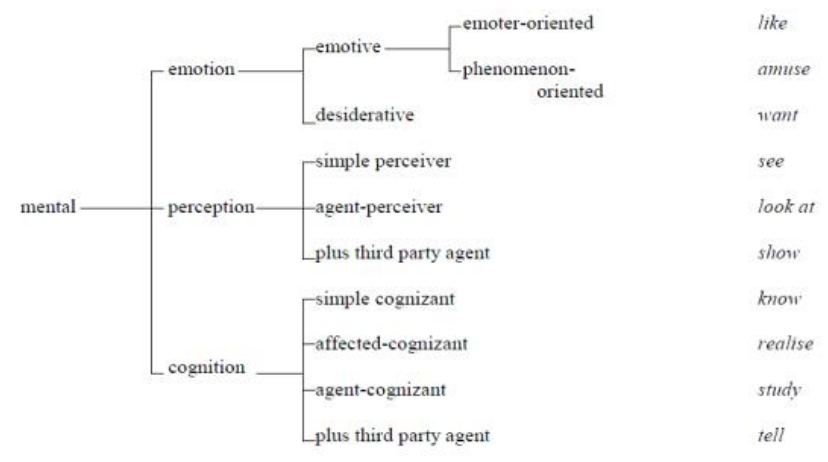

Fig. 2. The major options in the 'mental' part of the transitivity network adopted from Fawcett (2002).

The problem in "Fig. 2" may appear in the 'plus third party agent' with 'tell' since we know 'tell' is usually used in verbal processes. Examples in Group 4 show diverse interpretations of the verb 'tell'. In the first one, 'tell the difference' is a cognitive based processes while the second is a typical verbal process with the verbiage of 'that' clause.
Group 4:

1). She told the difference between infatuation and love.

2). She told me that she got a cold.

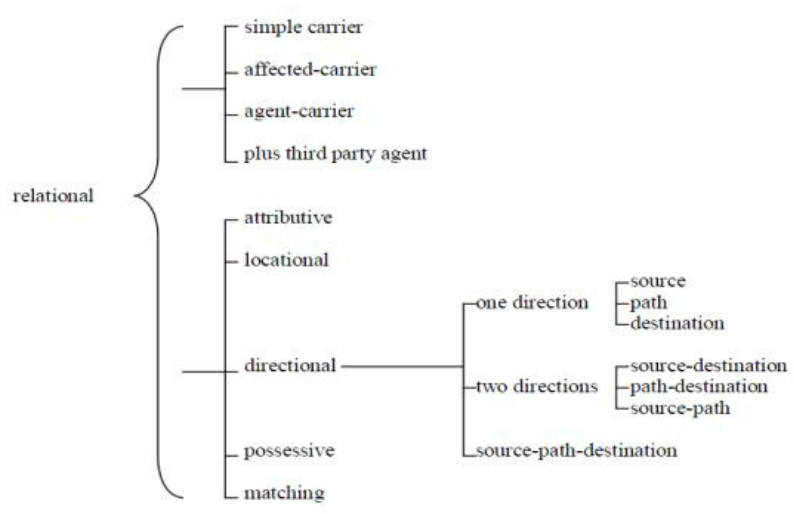

Fig. 3. The current System Network for Relational Processes adopted from Fawcett (2002).

Relational processes in "Fig. 3" contain mainly the attributive, locational, directional, possessive and matching processes according to Cardiff Grammar. We illustrate these subtypes in Group 5.

Group 5: Attributive

$\mathrm{Ca}+$ Pro + Loc: He is (or lives) in Beijing,

There + Pro $+\mathrm{Ca}+$ Loc: There's a fly in my soup.

Fawcett (2002) intent to include the existential processes with 'there be' structure in the attributive subtypes, while other authors like Teruya (2007), argues that existential processes can be considered as one of the subtypes within relational processes. That is to say, the attributive and the existential are two different subtypes.

Group 6: directional

$\mathrm{Ca}+$ Pro + Des: He has gone to Madrid

$\mathrm{Ag}+\mathrm{Pro}+\mathrm{Af}-\mathrm{Ca}+$ Des: He sent me to Madrid.

In the groups 6 , we have observed that the verb 'send' could be interpreted in two different ways. In the example of 'send me to Madrid', with the participant of the destination 'Madrid', we intent to categorize it into the directional subtype as one of the relational processes. While in the case of 'send me something', it is common to understand as a 
material processes with three participants. Therefore, sometimes, a concrete verb does not usually determinate the process type. And we have to take other factors such as tense, participants, etc. into account.

Group 7: possessive

$\mathrm{Ca}+$ Pro + Pos: He has a car.

Group 8: matching

$\mathrm{Ca}+$ Pro + Mtch: The key matches the keyhole.

\section{STYLISTIC ANALYSIS OF THE CHARACTER OF OWLS}

Halliday's analysis of The Inheritors shows that transitivity analysis in the ideational metafunctions is particularly emphasized in the novel and it plays a decisive role in the expression of the novel's theme-- the developing stages of man's controlling over the experiential world. For this paper, we focused on the Owls featured as one of the three animals that students are allowed to keep and as the postal service.

\section{A. Analysis of Concordance Lines}

We begin four examples below generated by WordSmith as concordance lines.

- - on the first morning, when about a hundred owls had suddenly streamed into

- - trate on drills that morning. He didn't see the owls swooping past in broad

- - or slammed in the next street, nor when two owls swooped overhead. In fact, it

- - is high chair. None of them noticed a large tawny owl flutter past the window.

From the concordance lines 1-4, we can find firstly owls fly due to the ordinary habit of the bird. In this group of processes, owls act as the agent in those intransitive material process clauses. So their actions don't affect other participants.

We have generated the following concordance lines by searching the keywords: package(s) with 21 examples and letter(s) with 88 examples.

- - the Slytherin table. A barn owl brought Neville a small package from his

- - of course. Malfoy's eagle owl was always bringing him packages of sweets

- - a long thin package carried by six large screech owls. Harry was just as

- - fluttered out of the way when another owl dropped a letter on top of the parcel

The concordance lines 5 to 8 are apparently transitive clauses. With those examples, we have discovered that the main purpose of all this flying is to deliver post. The aims as message carrying and post deliveries constitute the goal of in the material process.

- - away, won't you?' said Hermione. 'And send me an owl if you find anything.'

- - right, dear, well, have a good term - send me an owl when you get there.' She o cry.

- - ummer,' said Ron, 'both of you - I'll send you an owl.' 'Thanks,' said Harry.

- - my mother and father. 'Sent owls off ter all yer parents' old school friend

By searching the keywords like send or its past tense sent, we have been told owls are kept by human being and are under the control of human characters in Rowling's novel. So owls are sent by human beings as the goals of the clauses, while human acts as agent.

- - they make me sneeze. I'll get yer an owl. All the kids want owls, they're dead,

- - hardly ever wakes up. Percy got an owl from my dad for being made a Prefect,

- - - 'Hagrid!' said Harry loudly. 'There's an owl -' 'Pay him,' Hagrid grunted into

In the examples 13 and 14, owls figure as goals of the material processes. We can see clearly that they have been regarded as the students' possessions. That is to say, students can get an owl. The concordance line 15 shows that Owls play part of Beneficiary when humans pay them for their work.

In the last two examples of relational and mental processes, we are informed that human could have an owl when they want owls. In the example 16, owls represent the possessions while human figure the possessor. In the example 17, owls act as the phenomena in the desiderative process (want).

- - like Harry's in front of him - and they had an owl. Heart hammering, Harry

- - I'll get yer an owl. All the kids want owls, they're dead useful carry yer post

\section{B. The Character of the Owls in Harry Potter}

After examining the examples of the three main transitivity processes, firstly we illustrate the experience of the owls in Fig. 4. We can conclude the overall character of the owls under Rowling's writings. First of all, as a bird, owls fly. But compared to other children's stories in which pigeons seem to be the massager, in Harry Potter owls fly to deliver posts for the magical school staffs and students as their 'employment.' Therefore, they should be kept and paid by related personnel. As such an important creature in the novel, everyone except the muggles who don't know the magic, wants to have it and of course it is required to have it. 


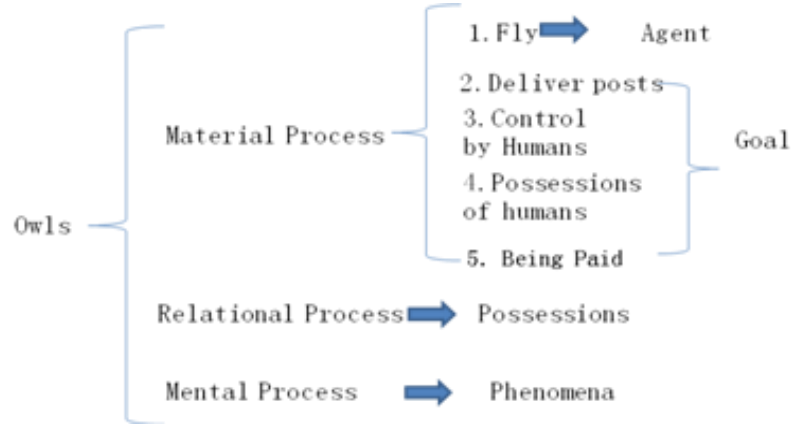

Fig. 4. The characteristics of the Owls.

In another figure "Table I", we have concluded the relations between owls and human beings because of the fastened connection.

TABLE I. RELATIONS BETWEEN OWLS AND HUMAN BEINGS

\begin{tabular}{|c|c|c|c|c|c|}
\hline $\begin{array}{l}\text { Types of } \\
\text { Process }\end{array}$ & Detailed & Roles of the Owls & $\begin{array}{l}\text { Types of the } \\
\text { Verbs }\end{array}$ & $\begin{array}{c}\text { Roles of Human } \\
\text { beings }\end{array}$ & $\begin{array}{l}\text { No. of } \\
\text { Roles }\end{array}$ \\
\hline \multirow{5}{*}{ Material } & FLY & Agent & Intransitive & $\mathrm{X}$ & 1 \\
\hline & Deliver Posts & Agent & Transitive & Beneficiary & 3 \\
\hline & $\begin{array}{l}\text { Control by } \\
\text { Humans }\end{array}$ & Goal & Transitive & Agent & 2 \\
\hline & $\begin{array}{l}\text { Being Kept by } \\
\text { Humans }\end{array}$ & Goal & Transitive & Agent & 2 \\
\hline & Being Paid & Beneficiary & Transitive & Agent & $2 / 3$ \\
\hline Relational & Possessive & Possession & Transitive & Possessor & 2 \\
\hline Mental & Emotion & Phenomenon & Transitive & Sensor & 2 \\
\hline
\end{tabular}

From "Table I", we can see the majority of the processes are transitive. That means at least it requires two participants (o roles). In the sense, most activities of the owls are affected by human beings except when owls fly by themselves without aims. Therefore, the owls, compared to other children's literature, are not wild and live in the forest. They do spend their life in the magical school with human beings. That could be the most highlighted difference of the character of owls in Harry Potter.

\section{CONCLUSION}

Systemic Functional Stylistics is literary stylistics, which describes the relationship between style, theme and aesthetic effects, so does SFS. Since the Transitivity Analysis is one of the most widely known methods used for stylistic analysis, we have attempted to use it in the discourse analysis, and attempted to make up for the deficiencies, so we have introduced the Attitude System into the functional stylistic analysis.

In this paper, we have tried to employ Transitivity system to depict the life of owls in order to discover their characteristics. Through the analysis of the material, relational and mental processes related to the owls, we acquire the idea that owls in Rowling's writing is not only a wild bird but also lives their life narrowly connected to the human beings. It can be found out that the message that J.K. Rowling wants to transmit hinders in these transitivity processes.
Apparently there have been problems and limitations in systemic stylistic analysis. In the analysis of material processes, language typologies could produce an asymmetry of the participants in the same process but distinct languages. Also, we need to pay attention to the tense of the relational process because changes of tense catalyze sometimes the categorization of the processes. And in the analysis of mental processes, we have met the difficulty in finding the standard patterns such as he thinks..., he senses.... When the clause lacks 'Senser+ Process' pattern, mental process may fail to be located by Wordsmith software. Finally, a concrete verb does not usually determinate the process type. We need to take other factors such as tense, participants, etc. into account for a more exact categorization. Further studies may focus on a thorough analysis of the processes types. Characteristics of other creatures in Harry Potter could be a series of research topics.

\section{REFERENCES}

[1] D. Shen, Transitivity and Hidden Symbolic Significance: Langston Hughes' "On the Road", Beijing: Foreign Language Teaching and Research, 2006.

[2] G. N. Leech and M. Short, Style in fiction: A linguistic introduction to English fictional prose (No. 13). Pearson Education, 2007.

[3] J. Hope and L. Wright, Stylistics: a practical coursebook. Routledge, 2002.

[4] J. K. Rowling, Harry Potter and the socerer's stone. Scholastic Inc,, 1998. 
[5] K. Teruya, A Systemic Functional Grammar of Japanese. 2 volumes. London: Continuum, 2007.

[6] L. Liu and W. X. Zhao, "Un estudio funcionalista del sistema de transitividad tipológica en las lenguas occidentales y orientales: los procesos relacionales con el verbo be en inglés, español, chino y japonés en Harry Potter I," In Actas del VIII congreso internacional de la Asociación Asiática de Hispanistas, Shanghai Foreign Language Education Press, 2015, 152-163.

[7] C. Li and X. Wang, A study of William Faulkner's time art from the perspective of mirror stage theory, Beijing: Foreign Language Teaching and Research, 2015.

[8] M.A.K. Halliday, "Linguistic function and literary style: an inquiry into the language of William Golding's The Inheritors", In S. Chatman , ed. Literary style: a symposium, 330-368. New York: Oxford University Press, 1971.

[9] M.A.K. Halliday, An Introduction to Functional Grammar. Beijing: Foreign Language Teaching and Research Press, 2000.

[10] R. Fawcett, The Functional Semantics Handbook: Analyzing English at the level of meaning. Continuum, 2002.

[11] T. Bloor and M. Bloor, The functional analysis of English: a Hallidayan approach. London: Arnold, 1995. 